\title{
Peripheral neuropathy in essential mixed cryoglobulinaemia
}

\author{
F Gemignani, G Pavesi, A Fiocchi, P Manganelli, G Ferraccioli, A Marbini
}

\begin{abstract}
The prevalence of various forms of peripheral neuropathy has not been previously assessed in large series of patients with essential mixed cryoglobulinaemia (EMC). Clinical and electrophysiological signs of peripheral neuropathy were observed in 21 of 37 EMC patients, consisting of polyneuropathy in 19, mononeuropathy or multiple mononeuropathy in eight, and both in six. The various forms of peripheral neuropathy occurred differently in the subgroups of EMC. Isolated polyneuropathy was more common with type II (eight of 10) than type III EMC (two of eight). Multifocal neuropathy, in association with polyneuropathy, was the most common form in type III EMC (five of eight). Patients with peripheral neuropathy and type II EMC were significantly older than type II EMC patients without neuropathy, regarding present age and age of onset of EMC. Patients with peripheral neuropathy and type III EMC tended to have higher values of ESR and IgM than type III EMC patients without neuropathy. Electrophysiological findings and sural nerve biopsy specimens (nine cases) showed prominent axonal changes. Vascular changes included vasculitis and alterations of the endoneurial microvessels in type II and type III EMC. Our findings suggest that distinct pathogenic factors are implicated in the subgroups of cryoglobulinaemic neuropathy, possibly inducing different types of vascular changes underlying polyneuropathy or, respectively, mononeuropathy and multiple mononeuropathy.
\end{abstract}

Institute of Neurology, University of Parma, Parma, Italy

F Gemignani

G Pavesi

A Fiocchi

A Marbini

Rheumatic Disease

Unit, University of

Parma, Parma, Italy

P Manganelli

G Ferraccioli

Correspondence to:

Dr Gemignani, Istituto di

Neurologia, Universitá di

Parma, via del Quartiere 4, I-

43100 Parma, Italy

Received 18 January 1991

and in revised form 19 April

1991.

Accepted 30 April 1991
Cryoglobulinaemia is a condition characterised by the presence of serum proteins reversibly precipitating in the cold, composed of isolated monoclonal immunoglobulin (cryoglobulin type I) or with a monoclonal component (type II) or composed only of polyclonal immunoglobulins (type III). ${ }^{1}$ Cryoglobulinaemia may be idiopathic (essential mixed cryoglobulinaemia (EMC)) or secondary to other diseases, such as lymphoproliferative disorders, collagen diseases, and chronic infections. ${ }^{1}$ Peripheral neuropathy associated with cryoglobulinaemia has long been described, ${ }^{2}$ most reports, however, deal with single cases ${ }^{3-14}$ or small groups of patients. ${ }^{15-20}$ The data on the prevalence of peripheral neuropathy in cryoglobulinaemia are inconsistent, ranging from quite low estimates $(7 \%-19 \%)^{151621}$ to about half the patients. ${ }^{2022}$ We examined a series of EMC patients to assess the prevalence of various forms of peripheral neuropathy and to evaluate factors possibly related to its occurrence. A report on the pathological findings in some of these patients has been published in abstract form. . $^{4}$

\section{Patients and methods}

Thirty seven consecutive unselected patients with EMC, followed either as inpatients or outpatients at the rheumatic disease unit of this hospital between January 1982 and June 1989, were clinically evaluated for symptoms and signs of peripheral neuropathy and submitted to electrophysiological study when peripheral neuropathy was clinically suspected. Laboratory studies included routine blood tests, immunological tests (immunoglobulin, WaalerRose reaction, latex test for IgM rheumatoid factor, C3 and C4, organ and non-organ specific antibodies), detection and characterisation of cryoglobulin according to Brouet et $a l^{1}$ and special investigations to assess involvement of other organs or to exclude possible causes of secondary cryoglobulinaemia. At the time of the study most patients were untreated or had had only a short course of steroid therapy. Peripheral neuropathy was clinically suspected when symptoms or signs of sensory or motor involvement, or both, were found within the territory of single nerves or with a diffuse distal limb distribution. On the basis of clinical and electrophysiological findings, peripheral neuropathy was classified as polyneuropathy, mononeuropathy or multiple mononeuropathy, ${ }^{25}$ Clinical and laboratory variables of neuropathic patients were analysed with regard to their possible relevance for the pathogenesis of peripheral neuropathy compared with the EMC patients without neuropathy as "control" group. Subgroups of patients with type II or type III EMC were segregated for further analyses. Student's unpaired $t$ test and Fischer's exact test were used for statistical comparison, and $p<0.05$ was considered significant.

Muscle examination with concentric needle electrode and nerve conduction studies were performed in 23 patients with clinically suspected neuropathy. Motor and sensory nerve conduction studies were performed with surface electrodes for stimulation and recording. Motor nerve conduction velocities (MNCV) and motor action potentials (MAP) were evaluated bilaterally in the peroneal nerve of all 
patients. Sensory conduction studies were performed antidromically in the sural nerves. Sensory action potentials (SAP) of the sural nerves were obtained by averaging 32-256 responses. MNCV of the median, ulnar, and tibial nerves and sensory nerve conduction velocities (SNCV) of the median, ulnar, and superficial peroneal nerves were also examined in selected patients. Electromyography (EMG) was performed with concentric needle electrodes in the distal muscles of the legs. When the neuropathy was focal or multifocal, the corresponding muscles and nerves were additionally examined. Limb temperature was maintained at $36^{\circ} \mathrm{C}$ with an infrared heating lamp throughout the examination. Biopsy specimens of the sural nerve $5 \mathrm{~cm}$ above the external malleolus and of the peroneus brevis muscle were obtained under local anesthesia in nine patients. Muscle and nerve biopsy specimens were processed with standard methods for histology, histochemistry, and electron microscopy, and for single fibre preparation (eight patients). ${ }^{26}$ Morphometric study of the distribution of myelinated fibre population was performed on photomicrographs of semithin sections at a magnification of $\times 1000$, covering at least $0.1 \mathrm{~mm}^{2}$ of endoneurial area, with an image analyser (MiniMOP, Zeiss Italia). Necrotising vasculitis was diagnosed according to the criteria of Wees et $a l^{27}$ and Dyck et $a l^{28}$ when intramural infiltration with necrosis of the vessel walls was present. Otherwise, pathological changes were considered suggestive but not diagnostic of vasculitis, or representative of healed vasculitis in the presence of infiltration or necrosis of the vessel wall, or perivascular inflammation, or fibrous scarring and intramural thickening of the vessel walls, ${ }^{2728}$ Direct immunofluores- cence on frozen nerve sections was performed with anti-sera coupled to fluorescein isothiocyanate.

\section{Results}

\section{Clinical findings}

A total of 37 EMC patients (33 women, four men) were examined during the study. Peripheral neuropathy was clinically suspected in 23 patients, but the diagnosis was confirmed in only 21 patients ( 17 women, four men) by electrophysiological investigation. Other possible causes of peripheral neuropathy were excluded. The 16 remaining women who did not show evidence of peripheral neuropathy, including two patients in whom electrophysiological examination was completely normal in spite of clinical suspicion of neuropathy, represented the "control" group of nonneuropathic EMC patients. Thus, peripheral neuropathy probably related to EMC was found in 21 out of 37 patients $(56.8 \%)$, with a prevalence similar or slightly lower than other common manifestations of EMC in our series, such as purpura (70.3\%), arthritis $(67.6 \%)$, and fever $(48.6 \%)$. The time elapsed between onset of EMC and clinical observation was similar in patients with peripheral neuropathy (range 4 months -30 years; median 2 years) and in "controls" (range 3 months-27 years; median $2 \cdot 5$ years).

Table 1 summarises the clinical features of peripheral neuropathy. Polyneuropathy was present in 19 patients, seventeen had a pure or mainly sensory type characterised by painful dysesthesias and sensory loss in a stocking distribution. Although polyneuropathy was often asymmetrical, extensive mononeuritis multiplex was excluded as temporal and spatial

Table 1 Features of patients with EMC and peripheral neuropathy

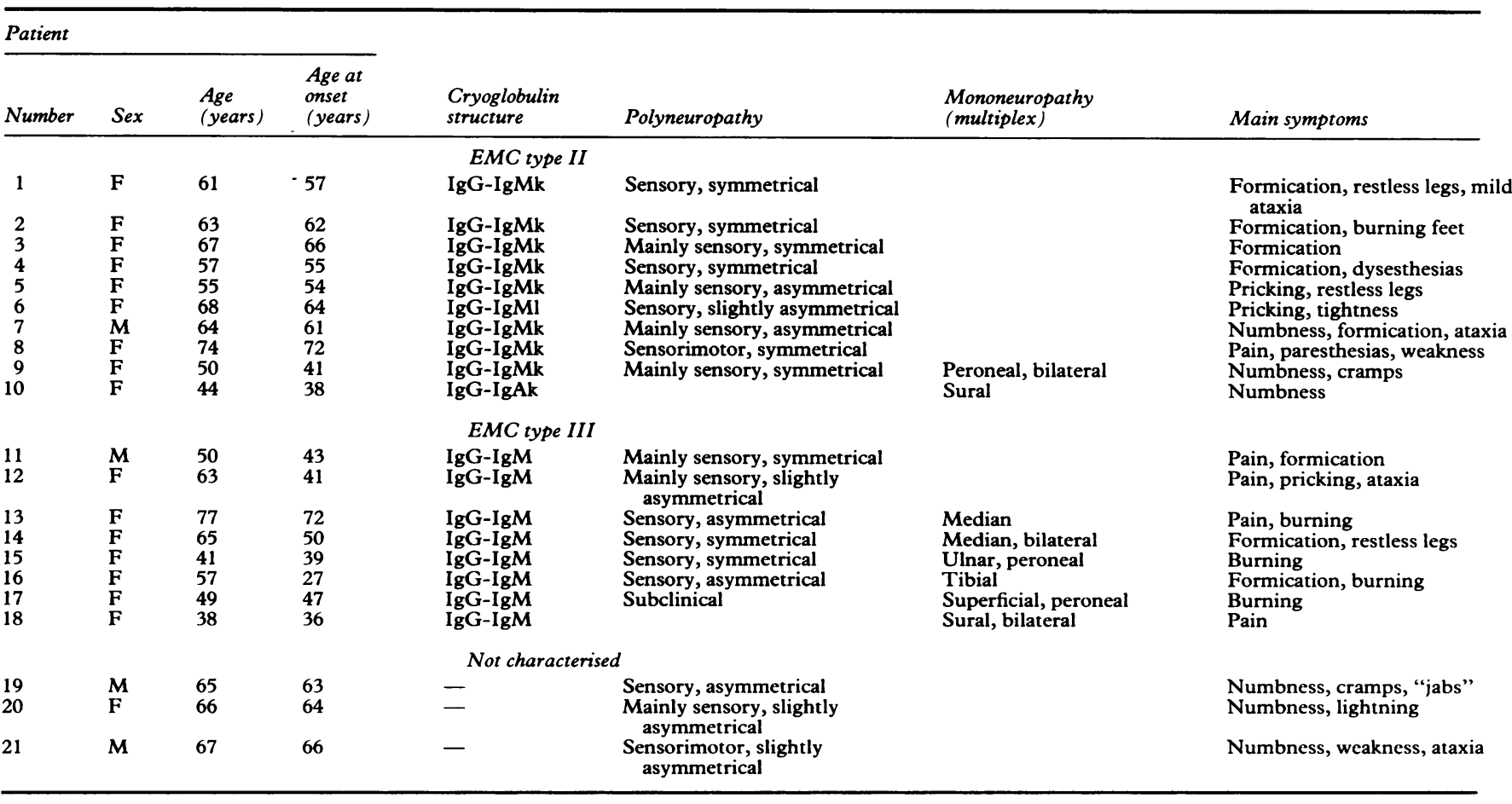


patterns of symptoms and deficits did not suggest diffuse nerve involvement from overlapping damage of specific nerves. ${ }^{28} 29$ Mononeuropathy or multiple mononeuropathy was seen in eight patients, generally with coexisting polyneuropathy (six patients). Peripheral neuropathy was the first manifestation of EMC in seven patients, alone in four or associated with purpura (two patients), arthritis, fever, and weight loss. In the 14 other patients peripheral neuropathy was preceded by other manifestations of EMC - such as, purpura (12 patients), arthritis (four patients), fever (three patients), weight loss (one patient), Raynaud's phenomenon (one patient)-with an interval of 2-60 months (median 15 months).

Examining the peripheral neuropathy group as a whole, we found no significant difference in clinical and laboratory variables with the controls. We thus analysed separately neuropathic patients with EMC of type II (10 cases) and type III (eight cases), in comparison with the respective groups of non-neuropathic patients (seven patients in each subgroup). Due to the small amount of the cryoprecipitate, cryoglobulin could not be characterised in three neuropathic and two non-neuropathic patients, who were not considered in further analyses. The distribution of subtypes of peripheral neuropathy differed in the EMC subgroups. Multiple mononeuropathy (with or without polyneuropathy) was more common in type III (six of eight) than in type II EMC $(p=0.03)$. Pure polyneuropathy was more common with type II (eight of 10) than type III EMC $(p=0.03)$. An association of (multi) focal neuropathy and polyneuropathy was more common in type III (five of eight) than type II EMC $(p=0.3)$. Patients with peripheral neuropathy and type II EMC were significantly older than controls with type II EMC, either at onset of EMC (mean (SD) years 57 $(10.7) v 42.7(12.5) ; \mathrm{p}<0.05)$ or present age $(60.3(8.9) v 49 \cdot 7(7 \cdot 8) ; \mathrm{p}<0.05)$. Comparison of laboratory findings showed that in neuro- pathic patients with type III EMC values of ESR and serum Ig $M$ tended to be higher than in the type III EMC control group: however, the difference was not significant (mean (SD) ESR 31(30) $v 16(9) \mathrm{mm} / \mathrm{hr}$ and mean (SD) IgM $4.6(2.4) v 2 \cdot 1(1.3) \mathrm{g} / 1)$. The distribution of associated symptoms of EMC was similar in the various subgroups, as well as the incidence of abnormal laboratory variables, including tests for IgM rheumatoid factor, serum complement, organ and non-organ specific antibodies, and packed cell volume. A follow up of at least one year after the initiation of therapy was available for 13 neuropathic patients (six treated with steroids, four with interferon $\alpha$, one with cyclophosphamide, two with association of steroids and interferon $\alpha$ ). From a clinical viewpoint, polyneuropathy symptoms did not seem to be influenced by the treatment: however, acute episodes of mononeuropathy seemed to be prevented. Painful or annoying sensory symptoms were successfully treated with amitryptiline in 10 patients.

\section{Electrophysiological findings}

Table 2 shows the results of the electrodiagnostic study. Patients 2 and 11 (not included in the table) had electrophysiological examination confirming polyneuropathy performed at another laboratory. The most relevant finding consisted in abnormal SAP of the sural nerve in all 18 examined patients, bilaterally in 14 of 17 , with completely absent SAP in eight (bilaterally in four of 17). SNCV was often preserved (10 patients), suggesting that SAP impairment was mainly due to axonal degeneration. MNCV of the peroneal nerve was abnormal in eight out of 19 patients, with severe impairment in only three cases, whereas decreased MAP amplitude was more often found (10/19). In some patients (numbers 13, 14, 15, 16), additional nerves which appeared clinically affected were examined, confirming focal or multifocal involvement, whereas in patient 18 the electrophysiological study of the superficial

Table 2 Electrophysiological findings

\begin{tabular}{|c|c|c|c|c|c|c|c|c|c|c|}
\hline \multirow{3}{*}{$\begin{array}{l}\text { Patient } \\
\text { number }\end{array}$} & \multicolumn{4}{|c|}{ Peroneal nerve } & \multicolumn{4}{|c|}{ Sural nerve } & \multirow{2}{*}{\multicolumn{2}{|c|}{$\begin{array}{l}\text { EMG } \dagger \text { of } \\
\text { distal muscles }\end{array}$}} \\
\hline & \multicolumn{2}{|c|}{$M N C V(m / s)$} & \multicolumn{2}{|c|}{ MAP amplitude $(m V)$} & \multicolumn{2}{|c|}{$S N C V(m / s)$} & \multicolumn{2}{|c|}{ SAP amplitude (uV) } & & \\
\hline & $\overline{R i g h t}$ & Left & $\overline{R i g h t}$ & $\overline{L e f t}$ & Right & Left & Right & Left & Right & Left \\
\hline 1 & $45 \cdot 0$ & $47 \cdot 0$ & $5 \cdot 0$ & $5 \cdot 0$ & $36 \cdot 2$ & $33 \cdot 3$ & $2 \cdot 0^{\star}$ & $3.5^{\star}$ & +++ & +++ \\
\hline 3 & 42.9 & $45 \cdot 6$ & $3 \cdot 0^{\star}$ & $4 \cdot 1$ & Absentf & $34 \cdot 2$ & $0^{\star}$ & $3 \cdot 0^{\star}$ & +++ & ++ \\
\hline 4 & $39 \cdot 1^{\star}$ & $31 \cdot 8^{\star}$ & $0.5^{\star}$ & $0.5^{\star}$ & Absent $f$ & Absent & $0^{\star}$ & $0^{\star}$ & +++ & $++t$ \\
\hline 5 & $38 \cdot 0^{\star}$ & $39 \cdot 0^{\star}$ & $2 \cdot 5^{\star}$ & $2 \cdot 0^{\star}$ & & & & & ++ & ++ \\
\hline 6 & $38 \cdot 5^{\star}$ & $38 \cdot 5^{\star}$ & $4 \cdot 0$ & $1 \cdot 2^{\star}$ & $40 \cdot 0$ & Absent & $0.5^{\star}$ & $0 \star$ & ++ & $++t$ \\
\hline 7 & $45 \cdot 8$ & 43.0 & $13 \cdot 0$ & 12.0 & Absent $f$ & 34.0 & $0^{\star}$ & $3 \cdot 0^{\star}$ & +++ & +++ \\
\hline 8 & $40 \cdot 0^{\star}$ & $41 \cdot 2^{\star}$ & $2 \cdot 9^{\star}$ & $1 \cdot 0^{\star}$ & $33 \cdot 1$ & $36 \cdot 2$ & $1 \cdot 0^{\star}$ & $1 \cdot 4^{\star}$ & $++t$ & +++ \\
\hline 9 & $44 \cdot 7$ & $44 \cdot 7$ & 6.5 & $9 \cdot 0$ & $46 \cdot 8$ & $38 \cdot 5$ & $4 \cdot 6^{\star}$ & $4 \cdot 6^{\star}$ & +++ & +++ \\
\hline 10 & 49.0 & 52.0 & $4 \cdot 8$ & $5 \cdot 5$ & $38 \cdot 4$ & $44 \cdot 0$ & $6 \cdot 0^{\star}$ & $18 \cdot 0$ & + & + \\
\hline 12 & $30 \cdot 0^{\star}$ & $27 \cdot 0^{\star}$ & $1 \cdot 0^{\star}$ & $0 \cdot 3^{\star}$ & Absent & Absent & $0^{\star}$ & $0^{\star}$ & +++ & +++ \\
\hline 13 & 46.0 & 42.8 & $3 \cdot 0^{\star}$ & $1 \cdot 8^{\star}$ & $43 \cdot 3$ & & $0 \cdot 6^{\star}$ & & +++ & ++ \\
\hline 14 & 44.5 & 45.9 & $10 \cdot 0$ & 13.0 & $37 \cdot 5$ & $37 \cdot 8$ & $8 \cdot 0$ & $6 \cdot 0^{\star}$ & + & + \\
\hline 15 & $30 \cdot 0^{\star}$ & Absent ${ }^{\star}$ & $0 \cdot 3^{\star}$ & $0^{\star}$ & Absent & Absentt & $0^{\star}$ & $0^{\star}$ & +++ & $++t$ \\
\hline 16 & $49 \cdot 0$ & $49 \cdot 4$ & $4 \cdot 8$ & 3.9 & $39 \cdot 0$ & $40 \cdot 8$ & $2 \cdot 0^{\star}$ & $2 \cdot 5^{\star}$ & & \\
\hline 17 & 43.8 & 47.6 & 3.8 & $4 \cdot 3$ & $40 \cdot 5$ & $39 \cdot 7$ & $6 \cdot 0^{\star}$ & $4 \cdot 9^{\star}$ & - & + \\
\hline 18 & $47 \cdot 7$ & $48 \cdot 0$ & $7 \cdot 0$ & 3.5 & Absentł & Absent $\ddagger$ & $0^{\star}$ & $0^{\star}$ & + & + \\
\hline 19 & $38 \cdot 0^{\star}$ & $36 \cdot 0^{\star}$ & 5.9 & $2 \cdot 0^{\star}$ & 36.7 & $35 \cdot 7$ & $0.5^{\star}$ & $1 \cdot 0^{\star}$ & +++ & +++ \\
\hline 20 & $47 \cdot 0$ & $45 \cdot 0$ & $5 \cdot 0$ & $5 \cdot 5$ & $36 \cdot 5$ & $39 \cdot 7$ & $5 \cdot 0^{\star}$ & $7 \cdot 0$ & ++ & ++ \\
\hline 21 & $32 \cdot 2^{\star}$ & $33 \cdot 1^{\star}$ & $3 \cdot 0^{\star}$ & $1.5 \star$ & Absent & $27 \cdot 4^{\star}$ & $0 \star$ & $5 \cdot 0^{\star}$ & ++ & ++ \\
\hline
\end{tabular}

^Normal values of peroneal nerve: $\mathrm{MNCV}=43 \mathrm{~m} / \mathrm{s} ;$ MAP amplitude more than $3.0 \mathrm{mV}{ }^{30}$

Normal values of sural nerve age-adjusted data from our laboratory, ranging from $>33 \mathrm{~m} / \mathrm{s}$ (age 40 ) to $30 \mathrm{~m} / \mathrm{s}$ (age 70 ) for $\mathrm{SNCV}$ and from $11 \mathrm{uV}$ (age 40 ) $50 \mathrm{uV}$

(age 70) for SAP amplitude.

†Abnormal findings. 
peroneal nerves yielded normal results, confirming a multiple mononeuropathy limited to the sural nerve bilaterally. Compression at the usual entrapment sites was excluded. In five patients with isolated polyneuropathy (numbers $6,7,12,19,21$ ), the nerves of the upper limbs were examined in addition to peroneal and sural nerves, showing abnormal motor and sensory examination of the median and ulnar nerve in two of them (patients 12 and 21) as features of subclinical polyneuropathy of the upper limbs. In all 18 patients abnormal EMG findings, of variable severity, were constantly observed in the distal muscles of the lower limbs, even in patients with normal electroneurographic examination of the peroneal nerves.

\section{Neuropathological findings}

Sural nerve biopsy specimens showed myelinated fibre loss mainly affecting large fibres (table 3 ). In four patients there was a severe fibre loss of all calibres, with a patchy fascicular distribution in patient 15. Myelinated fibre count was globally normal in patients 1,7 , and 9 as large fibre loss was compensated for by an increase of small fibres due to the presence of clusters of regenerating fibres. Active axonal degeneration was prominent in three biopsy specimens (patients 5, 6, and 18), and in the others previous axonal degeneration was suggested by fibre loss or regeneration. Minor features of demyelination or remyelination were often associated, and concentric whorls of supernumerary Schwann cells were noted in three specimens (patients 1, 12, 15). Unmyelinated fibres were involved only in more severely damaged nerves (patients 5, 6, 18). Changes of the endoneurial microvessels, consisting of thickening of the vessel walls and obliteration of the lumen, were seen in all specimens but were especially severe in four (patients $1,5,9$, 12). Scattered erythrocytes around endoneurial capillaries ("endoneurial purpura"19 were seen in patient 12). Necrotising vasculitis of the epineurial arterioles was present in two specimens (patients 5, 15), whereas in four others (patients $7,9,12,18$ ) there were signs of probable or healed vasculitis. Severe changes of the endoneurial vessels were more common in type II EMC (3/5 v 1/3), whereas vasculitis tended to be more common in type III EMC (3/3 $v 3 / 5)$. A sufficient number of teased fibres were available for examination in five biopsy specimens, whereas in three others no fibre could be isolated due to severe myelinated fibre loss (table 3). Axonal degeneration coexisted with variable degrees of segmental demyelination and remyelination, possibly secondary to axonal degeneration or atrophy. ${ }^{33-35}$ Direct immunofluorescence examination showed IgM deposits in the epineurial vessel walls in patient 12 and in the endoneurial vessels in patient 5 , whereas it was negative in patients 9 and 15 . In all examined patients peroneus brevis muscle biopsy specimens showed denervation of variable entity. Muscle vasculitis was seen in five. Tubulfilamentous structures within the basement membranes of muscle vessels probably representing cryoglobulin were observed on electron microscopy in patient 6 .

\section{Discussion}

Previous works reported clinico-pathological findings in small groups of patients ${ }^{17-19}$ or estimated the prevalence of peripheral neuropathy in cryoglobulinaemia, ${ }^{15} 16^{20-23}$ however, distinction was not always made between EMC and secondary cryoglobulinaemia. ${ }^{151618}$ Our study demonstrated a high prevalence of peripheral neuropathy in EMC (56.8\%) and a more common occurrence of polyneuropathy $(51.4 \%)$ than of mononeuropathy and multiple mononeuropathy $(21.6 \%)$, with association of both in $16.2 \%$. Peripheral neuropathy was the presenting manifestation of EMC in $18.9 \%$ of cases, more often than previously reported $\left(12.5 \%\right.$ according to Gorevic et al $\left.{ }^{21}\right)$. Polyneuropathy was generally of sensory type $(45.9 \%)$ commonly with features of painful dysesthesias. Similarly, peripheral neuropathy was found in half the cases of EMC by Migliorini et $a^{22}$ and by Garcia-Bragado et al $^{20}$; however, the data of Garcia-Bragado et al were obtained from a small group of 16 EMC patients, and five out of seven patients with peripheral neuropathy had a severe hepatopathy, which may be a cause of polyneuropathy. ${ }^{36}$ In the other prevalence studies, ${ }^{12123}$ neurological data were not detailed, so that the features of peripheral neuropathy and the respective occurrence of polyneuropathy or mononeuropathy and multiple mononeuropathy cannot be deduced. Valli et al $^{23}$ reported a high incidence $(60.9 \%)$ of mild peripheral nervous system involvement, examining 23 nephropathic patients with EMC. Definite peripheral neuropathy, how-

Table 3 Sural nerve biopsy findings

\begin{tabular}{|c|c|c|c|c|c|}
\hline \multirow{2}{*}{$\begin{array}{l}\text { Patient } \\
\text { number }\end{array}$} & \multirow{2}{*}{$\begin{array}{l}\text { Density of } \\
\text { myelinated } \\
\text { fibres }\end{array}$} & \multirow{2}{*}{$\begin{array}{l}\text { Myelinated } \\
\text { fibres } \\
(>7 \mu m(\%))\end{array}$} & \multicolumn{3}{|c|}{ Abnormalities in teased fibres $(\%)^{\star}$} \\
\hline & & & $A+B$ & $C+D+F+G$ & $E+H$ \\
\hline 1 & 6061 & $0 \cdot 8$ & 50 & 31 & 19 \\
\hline 5 & 1528 & $21 \cdot 5$ & $\bar{c}$ & - & - \\
\hline 6 & 2112 & $8 \cdot 2$ & 63 & 16 & 21 \\
\hline 7 & 6865 & $19 \cdot 5$ & 75 & 18 & 7 \\
\hline 9 & 6821 & $3 \cdot 4$ & Not done & & \\
\hline 12 & 2765 & 1.5 & $73 \cdot 5$ & $13 \cdot 5$ & 13 \\
\hline 15 & 3539 & $1 \cdot 1$ & - & - & - \\
\hline 18 & Myelinated & dally absent & - & - & - \\
\hline & 3466 & $9 \cdot 4$ & 72 & $20 \cdot 5$ & $7 \cdot 5$ \\
\hline Controls $†$ & $5400-8600 /$ & $32-45$ & 89 (SD 9) & $9(\mathrm{SD} 9)$ & $0.5(\operatorname{SD~} 0.5)$ \\
\hline
\end{tabular}

${ }^{\star}$ Classification of teased fibres: $\mathrm{A}=$ normal; $\mathrm{B}=$ myelin wrinkling; $\mathrm{C}=$ demyelination; $\mathrm{D}=$ de-remyelination; $\mathrm{E}=$ axonal degeneration; $F=$ remyelination; $G=$ myelin reduplication; $H=$ regeneration."

+ Normal values of myelinated fibre population according to Behse and Buchthal ${ }^{32}$; distribution of teased fibre changes in controls according to Ohi et al. . $^{32}$ 
ever, was demonstrated in only six patients. In our opinion, discrepancy within studies showing low prevalence $(7 \%-19 \%)$ of cryoglobulinaemic neuropathy, ${ }^{151621}$ may be due to overlooking mild forms and in particular subjective sensory symptoms.

Nerve biopsy specimens showed prominent axonal degeneration in accord with electrophysiological investigation and with previous pathological studies. ${ }^{91016-20232437}$ Vascular changes, previously stressed by others, ${ }^{9} 141618-203738$ consisted of vasculitis of the epineurial vessels or thickening and obliteration of the endoneurial vessels. The former aspect seems to represent immune complexmediated vasculitis ${ }^{39} 40$ whereas the changes of endoneurial microvessels could be due to a different mechanism. Nemni et al ${ }^{18}$ ascribed to vascular inflammation the changes of the endoneurial capillaries, which are not, however, in the size range of vessels expected to be affected by vasculitis $(50-300 \mu \mathrm{m}) .{ }^{29}{ }^{39}$ The role of ischaemia in the pathogenesis of cryoglobulinaemic neuropathy is well established, ${ }^{1618-20}{ }^{37}$ whereas other possible mechanisms, such as immunologically mediated nerve damage, remain unsupported. ${ }^{18} 197$ Our study showed that different forms of peripheral neuropathy are associated with the subtypes of EMC - that is, isolated polyneuropathy in type II EMC and (multiple) mononeuropathy, often combined with polyneuropathy, in type III EMC. In type II EMC patients, old age represented a significant risk factor for peripheral neuropathy, whereas neuropathic patients with type III EMC tended to have increased ESR and serum IgM levels. As multifocal neuropathies are often related to vasculitis of the vasa nervorum, ${ }^{25}$ and microangiopathy may cause polyneuropathy ${ }^{41}$ possibly the different forms of peripheral neuropathy in EMC are related to different patterns of vascular involvement. Indeed, type II cryoglobulins are immune complexes containing monoclonal rheumatoid factor, which fix C3 and $\mathrm{C} 4$ poorly causing tissue deposition ${ }^{42}$ rather than inflammatory reaction, and this could account for endoneurial vessel changes, similar to the putative mechanism involved in the damage of glomerular capillaries. ${ }^{11}$

1 Brouet J-C, Clauvel J-P, Danon F, et al. Biologic and clinical significance of cryoglobulins. A report of 86 cases. Am J Med 1974;57:775-88.

2 Garcin R, Mallarmé J, Hartmann L, et al. Cryoglobulinémie et névrite multiple des membres inférieurs. Bull Soc Med 1957;73:815-44

3 Siguier F, Godeau P, Lévy R, et al. A propos d'un cas de cryoglobulinémie (étude clinique et biologique). Sem Hop 1964;40:1928-34.

4 Dayan AD, Lewis PD. Demyelinating neuropathy in macrocryoglobulinemia. Neurology 1966;16:1141-4.

5 Farivar M, Wands JR, Benson GD, et al. Cryoprotein complexes and peripheral neuropathy in a patient with

6 Benjamin D, Douer D, Pick A, et al. Peripheral cryoglobulinemic neuropathy in a patient with Gaucher's disease. Acta Haematol 1978;60:117-21

7 Vallat JM, Desproges-Gotteron R, Leboutet MJ, et al. Cryoglobulinemic neuropathy: a pathological study. Ann Neurol 1980;8:179-85.

8 Betourné C, Buge A, Dechy $\mathrm{H}$, et al. Neuropathies périphériques au cours d'un myelome á IgA et d'une cryoglobulinemie mixte: traitement par plasma-phérèses iteratives. Presse Méd 1980;9:1369-71.

9 Chad D, Pariser K, Bradley WG, et al. The pathogenesis of cryoglobulinemic neuropathy. Neurology 1982;32:725-9.

10 Kohnishi T, Saida K, Ohnishi A, Nishitani H. Perineuritis in mononeuritis multiplex and cryoglobulinemia. Muscle in mononeuritis mul.

11 Feiner HD. Relationship of tissue deposits of cryoglobulin to clinical features of mixed cryoglobulinemia. Hum Pathol 1983;14:710-5.

12 Lippa CF, Chad DA, Smith TW, et al. Neuropathy associated with cryoglobulinemia. Muscle Nerve 1986;9: 626-31.

13 Testa D, Salmaggi A, Eoli M, et al. Cryoglobulinemic neuropathy: case report. Ital J Neurol 1988;9:391-5.

14 Barbieri F, Sinisi L, Santangelo R, et al. Cryoglobulinemic neuropathy. A light and electron microscopic study. Acta Neurol 1989;11:241-8.

15 Logothetis J, Kennedy WR, Ellington A, Williams RC. cryoglobulinemic neuropathy: incidence

16 Cream JJ, Hern JEC Hughes RAC, Mackenzie ICK. Mixed or immune complex cryoglobulinemia and neuropathy. or immune complex cryoglobulinemia and
$J$ Neurol Neurosurg Psychiatry 1974;37:82-7.

17 Geraud G, Lacrergue JP, Bes A, et al. Neuropathies périphériques associées à une cryoglobulinémie. J Neurol Sci phériques associes

18 Nemni R, Corbo M, Fazio R, et al. Cryoglobulinemic neuropathy. A clinical, morphological and immunocytochemical study of 8 cases. Brain 1988;111:541-52.

19 Vital C, Deminière C, Lagueny A, et al. Peripheral neuropathy with essential mixed cryoglobulinemia: biopsies from 5 cases. Acta Neuropathol 1988;75:605-10.

20 Garcia-Bragado F, Fernandez JM, Navarro C, et al. Peripheral neuropathy in essential mixed cryoglobulinemia. Arch Neurol 1988;45:1210-4.

21 Gorevic PD, Kassab HJ, Levo Y, et al. Mixed cryoglobulinemia: clinical aspects and long-term follow-up. Am J Med 1980;69:287-308.

22 Migliorini P, Bombardieri S, Castellani A, et al. HLA antigens in essential mixed cryoglobulinemia. Arthritis antigens in essential

23 Valli G, DeVecchi A, Gaddi L, et al. Peripheral nervous system involvement in essential cryoglobulinemia and system involvement in essential cryoglobulinem

24 Gemignani F, Marbini A, Cersosimo A, et al. Pathological study of cryoglobulinemic neuropathy. Ital J Neurol Sci 1986;7:288.

25 Parry GJG. Mononeuropathy multiplex (AAEE case report no 11). Muscle Nerve 1985;8:493-8.

26 Gemignani F, Marbini A, Bragaglia MM, Govoni E. Pathological study of the sural nerve in Fabrys's disease. Eur Neurol 1984;23:173-81.

27 Wees SJ, Sunwoo IN, Oh SJ. Sural nerve biopsy in systemic necrotizing vasculitis. Am J Med 1981;71:525-32.

28 Dyck PJ, Benstead TJ, Conn DL, et al. Nonsystemic vasculitic neuropathy. Brain 1987;110:843-54.

$29 \mathrm{Kissel}$ JT, Slivka AP, Warmolts JR, Mendell JR. The clinical spectrum of necrotizing angiopathy of the periclinical spectrum of necrotizing angiopathy of the

30 Rosenfalck P, Rosenfalck R. Electromyography. Sensory and motor conduction findings in normal subjects. Copenhagen: motor conduction findings in normal subjects. Coper

31 Dyck PJ, Karnes J, Lais A, et al. Pathologic alterations of the peripheral nervous system of humans. In: Dyck PJ Thomas PK, Lambert EH, Bunge R, eds. Peripheral neuropathy. Vol 1. 2nd ed. Philadelphia: Saunders, 1984:
760-870.

32 Behse F, Buchthal F. Alcoholic neuropathy: clinical, electrophysiological and biopsy findings. Ann Neurol 1977;2: 95-110.

33 Ohi T, Kyle RA, Dyck PJ. Axonal attenuation and secondary segmental demyelination in myeloma neuropathies. Ann Neurol 1985;17:255-61.

34 Thomas PK, Hollinrake K, Lascelles RG, et al. The polyneuropathy of chronic renal failure. Brain 1971;94: 761-80

35 Dyck PJ, Johnson NJ, Lambert EH, O'Brien PC. Segmental demyelination secondary to axonal degeneration in uremic demyelination secondary to axonal degeneration in

36 Asbury AK. Hepatic neuropathy. In: Dyck PJ, Thomas PK, Lambert EH, Bunge R, eds. Peripheral neuropathy. Vol 2. 2nd ed. Philadelphia: Saunders, 1984:1826-32.

37 Cavaletti G, Petruccioli MG, Crespi V, et al. A clinicopathological and follow-up study of 10 cases of essential type II cryoglobulinemic neuropathy. J Neurol Neurosurg Psychiatry 1990;53:886-9.

38 McLeod JG, Walsh JC, Pollard JD. Neuropathies associated with para-proteinemias and dysproteinemias. In: Dyck PJ, Thomas PK, Lambert EH, Bunge R, eds. Periphera neuiopathy. Vol 2. 2nd ed. Philadelphia: Saunders, 1984 $1847-65$.

39 Cupps TR, Fauci AS. Pathophysiology of vasculitis. In: The vasculitides. Philadelphia: Saunders, 1981:6-19.

40 Moore PM. Immune mechanisms in the primary and secondary vasculitides. J Neurol Sci 1989;93:129-45.

41 Yasuda $\mathrm{H}$, Dyck PJ. Abnormalities of endoneurial microvessels and sural nerve pathology in diabetic neuropathy. Neurology 1987;37:20-8.

$42 \mathrm{Ng} \mathrm{YC}$ Peters DK, Walport MJ. Monoclonal rheumatoid factor-IgG immune complexes. Poor fixation of opsonic $\mathrm{C} 4$ and C3 despite efficient complement activation. Arthritis Rheum 1988;31:99-107. 